\title{
Jornalismo e direitos infantis no Brasil e em Portugal: privacidade, estigmatização e participação de crianças e adolescentes nos jornais O Globo e Público
}

LIDIA SORAYA BARRETO MARÔPO - lidiamaropo@gmail.com Universidade Autónoma de Lisboa - Portugal Doutora em Ciências da Comunicação pela Universidade Nova de Lisboa, professora da Universidade Autónoma de Lisboa e pesquisadora pós-doc do Centro de Investigação Media e Jornalismo/Universidade Nova de Lisboa.

\begin{abstract}
Resumo
A partir da análise de conteúdo de notícias veiculadas nos jornais O Globo (Brasil) e Público (Portugal), discutimos três questões centrais para o debate sobre jornalismo e direitos das crianças: privacidade, estigmatização e participação destas no discurso noticioso. Concluímos que a relação entre os jornais de referência analisados e os direitos da criança representa um paradoxo. Por um lado, os periódicos contribuem para maior visibilidade pública de temáticas e problemas que afetam diretamente as crianças mas, por outro, chamamos a atenção para a necessidade de evitar que esses mesmos veículos desrespeitem os direitos infantis.
\end{abstract}

Palavras-chave

Jornalismo, direitos da criança, jornalismo de referência.

\begin{abstract}
From the content analysis of $O$ Globo (Brazil) and Público (Portugal), we discuss three central issues to the debate on journalism and child rights: privacy, stigmatization and participation. We conclude that the relationship between the quality newspapers and children's rights is a paradox. On the one hand, the two newspapers contribute to the public visibility of issues and problems affecting children but, on the other, we call attention to prevent these same vehicles from disrespecting the rights of the children.
\end{abstract}

Keywords

Journalism, child rights, quality journalism

Artigo recebido em 25/08/2011

Aprovado em 10/10/2011 
ste artigo discute três questões centrais para a relação entre jornalismo e
direitos das crianças e adolescentes: o respeito pela privacidade (em situações
de risco ou que possam causar constrangimentos), a estigmatização (especialmente em relação a adolescentes provenientes de meios socioeconômicos desfavorecidos) e a participação (crianças como fontes de informação).

Fizemos uma análise de conteúdo das 293 chamadas ou manchetes de primeira página e das notícias correspondentes veiculadas no interior dos jornais $O$ Globo (150) e Público (143) em 2009 que abordavam temas relacionados diretamente às crianças. Estamos falando sobre duas publicações diárias de referência no Brasil e em Portugal, respectivamente, que se dirigem às elites políticas, econômicas e sociais, procuram exercer influência sobre estas e consequentemente sobre as agendas pública e política desses países. Mais do que uma análise quantitativa, interessa-nos aqui uma perspectiva qualitativa que permita perceber os processos e influências que interferem no agendamento e enquadramento de crianças, adolescentes e dos seus direitos nos dois jornais.

Elaboramos um questionário para análise das notícias e os dados foram tratados utilizando o programa de análise estatística SPSS. Foram consideradas variáveis de caráter mais formal (nome do jornal, a data e a editoria em que a peça foi publicada, por exemplo) e também relacionadas com o conteúdo (o título em primeira página e no interior do jornal, o tema, o jornalista autor, a quantidade e quem são as fontes utilizadas). Mas aqui analisamos mais especificamente um terceiro conjunto de variáveis relacionadas com os direitos das crianças: se a privacidade é respeitada nos casos de risco ou de potenciais constrangimentos (1. Divulgados nome e/ou imagem, 2. Identificação indireta e 3. Identidade preservada); se são utilizados termos ou expressões estigmatizantes e, por último, como são representadas as crianças como personagens das notícias: o sexo, a idade (0 a 11 anos - crianças e 12 a 17 anos adolescentes), o papel (1. Vítima, 2. Ameaça, 3. Alvo de cuidados e atenção, 4. 
Estudante, 5. Ator sociali, 6. Beneficiário/afetado por políticas públicas) e a voz (1. Ausente, 2. Relato pessoal sobre o tema em questão e 3. Análise do tema tratado).

É nosso propósito responder à seguinte questão: de que modo a imprensa de referência portuguesa e brasileira, representada aqui especificamente pelos jornais mencionados, se relaciona com os direitos das crianças? Ou, no dizer de Hammarberg (1997, p. 245), qual a posição direta ou indireta desses veículos sobre os direitos das crianças? Para o autor é possível entender essa posição a partir da forma como os jornais descrevem as crianças, como monitorizam os seus direitos, pela extensão e maneira como dão voz às crianças e o que fazem para evitar que eles próprios abusem das crianças.

As respostas a essas questões nos permitem analisar em que medida esses jornais contribuem (ou não) para o reconhecimento identitário das crianças como sujeitos de direitos e nos dão algumas pistas sobre o papel que o jornalismo vem exercendo nesse processo. Partimos do pressuposto de que o discurso noticioso é um elemento central para a manutenção e promoção das sociedades democráticas, que incluem (ou precisam incluir) crianças e adolescentes ( 0 a 18 anos) enquanto cidadãos em fase especial de desenvolvimento. Defendemos que o jornalismo deveria construir simbolicamente uma identidade infantil ativa e detentora não só dos chamados direitos de provisão e proteção (amplamente reconhecidos, mas frequentemente não efetivados), mas também dos direitos de participação (amplamente negligenciados).

A partir dessa percepção sobre o jornalismo, queremos saber em que medida e em que circunstâncias os referidos jornais superaram ou não as críticas à cobertura noticiosa sobre as crianças e os seus direitos apontadas na revisão de literatura que apresentamos a seguir.

\section{A representação de crianças e adolescentes nas notícias}

Embora se admita uma crescente visibilidade da infância no discurso noticioso, pesquisas recentes continuam a denunciar a subrepresentação mediática das crianças e a 
negligência dos assuntos relacionados com elas (FULLERTON, 2004; MULEIRO, 2006; MCNAMARA, 2004; GOONASEKERA, 2001; VON FEILITZEN, 1998). Essa visibilidade insuficiente (e desfocada) seria um reflexo do seu estatuto minoritário na sociedade e representa uma "opressão simbólica" das crianças (VON FEILITZEN, 1998), que na verdade não são uma minoria em termos quantitativos, já que as pessoas com idade até 18 anos somam aproximadamente $37 \%$ da população mundial.

No Brasil, até o início dos anos 90, Canela (2006, p. 36) afirma que a cobertura da infância e adolescência era "praticamente inexistente" nos jornais e a que existia ainda privilegiava a ótica repressora do antigo Código de Menores e ignorava a perspectiva dos direitos e da cidadania estabelecida pela Convenção dos Direitos da Criança (CDC, 1989), ratificada pelo Brasil, e pelo Estatuto da Criança e do Adolescente (1990), a nova legislação do país.

Em Portugal, Ponte (2005, p. 191) afirma que procurar notícias sobre crianças (a investigadora refere-se até a idade de 14 anos) na década de 1970 exige "bons olhos". Apesar da quantidade expressiva, os acidentes, abandonos e mortes de crianças são notícias sem destaque, com um ou dois parágrafos, em enquadramentos que privilegiam a "fatalidade" em detrimento do debate sobre a segurança infantil e as más condições de vida de milhares de crianças no país.

Essa situação de invisibilidade da infância como matéria noticiosa vem se alterando significativamente nas últimas décadas. Por um lado, as crianças estão mais presentes na cobertura jornalística a partir de uma agenda pública mundial pela infância que tem como marco o Ano Internacional da Criança (1979) e a Convenção dos Direitos da Criança (1989). A adaptação dos princípios da CDC para as leis e políticas públicas dos países incentiva a mobilização social e consequentemente uma maior visibilidade noticiosa da infância. No Brasil, o Estatuto da Criança e do Adolescente (1990) foi o marco legal que propiciou a mobilização dos movimentos de defesa dos direitos infantis como fontes de informação pró-ativas na promoção do debate sobre a temática na mídia. Em Portugal, mais recentemente, a Lei de Protecção de Crianças e Jovens em Perigo (1999) e a Lei Tutelar Educativa (2000), além da organização das comissões de proteção 
de crianças e jovens, também incentivaram uma maior contextualização e debate midiático sobre os problemas que afetam os cidadãos mais novos da sociedade.

Por outro lado, as transformações econômicas no polo da mídia a partir dos anos 80 (concentração, liberalização, aumento de concorrência e intensificação das lógicas de mercado) fortaleceram as orientações do jornalismo para o mercado e a necessidade de procurar novos leitores (PONTE, 2005, p. 85). Os jornais perceberam o crescente investimento afetivo das famílias na infância e, a par da feminização das redações, as crianças fazem parte do esforço de conquista do público feminino em notícias com informações utilitárias sobre como lidar e educar as "nossas crianças", a partir das vivências do cotidiano da classe média (PONTE, 2005, p. 89).

Nossa revisão de literatura também nos leva a crer que não é frequente que as temáticas da infância sejam abordadas numa perspectiva de direitos. Até há bem pouco tempo, assim como as mulheres, as crianças viviam "ocultas sob o manto do privado e do íntimo, um obstáculo ao seu reconhecimento público e social” (MARTIN, 2001, p. 2). Eram vistas como assunto individual das famílias e não apelavam a uma responsabilidade coletiva, não eram uma questão de debate público e político. Essa realidade vem se transformando mas, por outro lado, as prioridades comerciais da mídia e os constrangimentos diários da produção jornalística (como tempo, espaço e investimento) dificultam uma discussão mais profunda sobre a temática.

Além disso, estudiosos e ativistas alertam para situações em que a própria mídia funciona como violadora dos direitos infantis quando identifica direta ou indiretamente crianças e adolescentes em situações que possam prejudicar o seu desenvolvimento ou causar constrangimentos, quando promove a estigmatização de crianças e adolescentes (geralmente de classes desfavorecidas) ou quando inibe o direito destes de expressar seus pontos de vista sobre os assuntos que lhes dizem respeito (MARÔPO, 2010). A partir da análise de O Globo (OG) e Público (P), discutiremos a seguir sobre essas três questões. 


\section{O direito à privacidade}

No Brasil, o Estatuto da Criança e do Adolescente (Art. $17^{\circ}$ ) fala da preservação da imagem, da identidade, da autonomia, dos valores, ideias e crenças, dos espaços e objetos pessoais. O ECA afirma também que é "dever de todos velar pela dignidade da criança e do adolescente, pondo-os a salvo de qualquer tratamento desumano, violento, aterrorizante, vexatório ou constrangedor".

Em Portugal, a Lei de Protecção de Crianças e Jovens (Art. 90. ${ }^{\circ}$ ) afirma que os meios de comunicação social, sempre que divulguem situações de crianças ou jovens em perigo, não podem identificar, transmitir elementos, sons ou imagens que permitam a sua identificação. A Lei Tutelar Educativa (LTE), aplicável aos jovens com idade entre 12 e inferior aos 16 anos que cometem atos ilícitos, garante o direito destes à proteção de sua vida privada em todas as fases do processo (Art. $41^{\circ}$ ). Além disso, a Constituição da República Portuguesa (Art. $26^{\circ}$ ) reconhece, para todos, os direitos à privacidade pessoal, ao desenvolvimento da personalidade, à capacidade civil, à cidadania, ao bom nome e reputação, à imagem, à palavra, à reserva da vida privada e familiar e à proteção legal contra quaisquer formas de discriminação.

Os dois países são signatários da Convenção dos Direitos da Criança (Art. 16 ${ }^{\circ}$ ) que afirma o direito à proteção da privacidade e contra ataques à honra e à reputação das crianças. Nesta perspectiva, o tema também tem suscitado a preocupação da Federação Internacional dos Jornalistas (FIJ) que implementou nos anos 90 o projeto Child Rights and the Media e publicou diversas resoluções normativas sobre a cobertura envolvendo crianças. O respeito pela privacidade e preservação da identidade são questões centrais. Essas recomendações, no entanto, parecem ter pouca repercussão no Brasil e em Portugal, já que os documentos não estão traduzidos para o português, não há referências aos mesmos nos sites da Federação Nacional dos Jornalistas (BR) e do Sindicato dos Jornalistas (PT) ou em pareceres e comunicados produzidos pelas entidades relativamente à cobertura sobre a infância (MARÔPO, 2010, p. 184). 
Por outro lado, segundo a FIJ (1997), os códigos de ética dos dois países figuram entre os poucos que fazem menção direta às crianças. $O$ código português (1999) demonstra preocupação, embora limitada, com a privacidade dos mais novos. O artigo $7^{\circ}$ afirma que "o jornalista não deve identificar, direta ou indiretamente, as vítimas de crimes sexuais e os delinquentes menores de idade, assim como deve proibirse de humilhar as pessoas ou perturbar a sua dor". Não há referências diretas às crianças vítimas de crimes em geral ou que estão em situação de risco. O Código de Ética dos Jornalistas Brasileiros (Art. $6^{\circ}$ ) afirma ser dever do jornalista "defender os direitos do cidadão", e inclui crianças, adolescentes, mulheres, idosos, negros e minorias como grupos especiais de atenção.

No entanto, ainda é relativamente frequente o uso de marcas de identificação no discurso noticioso, especialmente quando este se refere a crianças em situação de exclusão ou que vivem distantes do campo de atuação da mídia em questão (MARÔPO, 2010, p. 109). A partir de entrevistas com 20 jornalistas e 22 fontes dos dois países, Marôpo (2010, p. 306) conclui que a exposição pública de crianças (especialmente as vitimizadas) é definida como a questão ética crucial da cobertura relacionada com esse grupo social em Portugal (Essa situação é referida de forma secundária no Brasil, onde os entrevistados identificaram a estigmatização de adolescentes excluídos como a dificuldade central). O problema, referem os entrevistados portugueses, parece ser reflexo não só de pressões comerciais ("o tema vende"), mas também do desconhecimento das leis ou negligência da sua aplicação pelos jornalistas e de uma inércia das fontes de informação para denunciar e combater o problema.

Nossos dados demonstram que do total de 72 peças publicadas nos dois jornais, que envolviam situações de risco ou que podiam causar constrangimentos para as crianças, 33 (45\%) preservavam a identidade destas (16 no P e 17 em OG). Nas demais houve identificação por meio do nome e/ou imagem em 8 itens (11\%) no periódico português e em $15(20 \%)$ no periódico brasileiro. Também registramos uma identificação indireta (pela divulgação do nome dos pais, por exemplo) em 9 itens 
(12\%), sendo 4 no P e 5 em OG. Uma análise mais detalhada dessas notícias nos leva a algumas conclusões.

Parece já haver um reconhecimento do direito à privacidade, previsto em leis internacionais, brasileiras e portuguesas, nos casos em que crianças ou adolescentes são protagonistas de atos violentos. No entanto, a regra parece não valer quando o delito é praticado fora desses países. Tanto o Público quanto $O$ Globo divulgaram a imagem e/ou o nome de um adolescente que matou 15 pessoas numa escola alemã. A morte deste rapaz após disparar os tiros também parece ser vista como outro fator que permite uma maior exposição da sua identidade, o mesmo tendo acontecido no texto Polícia alega legítima defesa na morte de jovem (6/Jan), no qual o Público identificou o adolescente referido neste título, pelo nome e sobrenome.

Os pais e/ou familiares também parecem exercer um papel central na decisão dos jornalistas de identificar ou não as crianças. Por um lado, quando estes exigem a preservação da privacidade familiar e dos filhos, os dois jornais tendem a respeitá-los. $\mathrm{O}$ Público explicita essa exigência como justificativa para a não divulgação de dados pessoais de pais acusados de abandonar os filhos. Por outro lado, quando os pais ou familiares utilizam a mídia como fórum de debate e instrumento de reivindicação pública em disputas pela guarda ou pelo reconhecimento de paternidade é quase inevitável que as crianças sejam identificadas indiretamente. Nos exemplos que encontramos, as suas imagens não são divulgadas, mas a exposição dos pais e/ou familiares possibilita essa identificação indireta, como demonstram os chamados "Caso Sean" e "Caso Alexandra", que tiveram grande repercussão, respectivamente no Brasil e em Portugal. A notoriedade dos pais (se são figuras públicas ou de elevado estatuto social) envolvidos em conflitos desta natureza é um forte valor-notícia para o agendamento dos casos e também para o desrespeito da privacidade das crianças.

A fonte promotora da notícia também demonstra ter um papel primordial na preservação da identidade das crianças. Quando a informação é promovida por uma fonte institucionalizada parece haver um maior cuidado, inclusive evitando a identificação indireta, como em itens que se referem a crianças que visitam os pais na 
prisão (P, 13/ago) ou que abordam o drama da AIDS em Moçambique (OG, 6/set). O mesmo acontece quando o assunto noticiado envolve referências a crianças sob a responsabilidade de instituições como hospitais e escolas.

Identificamos ainda o que parece ser uma atenção especial de $O$ Globo a crianças e adolescentes envolvidos em situações nas quais a sua identificação poderia significar não só uma estigmatização, mas também uma ameaça para a sua segurança, em notícias sobre temas como o tráfico de drogas e a exploração sexual. No entanto, os cuidados em ocultar os nomes e rostos podem não ser suficientes em textos que descrevem detalhes das "personagens" ou em imagens que revelam roupas, tatuagens ou outras marcas que podem facilitar a identificação.

Por último, destacamos também a dificuldade de encontrar o equilíbrio entre o direito à proteção das crianças e adolescentes e o direito destes de exercer um papel protagonista nas questões que lhes dizem respeito. Por exemplo, como conciliar a possibilidade destes usarem a mídia como fórum de debate e reivindicação ao mesmo tempo que a exposição pública pode ser uma fonte de estigmatização ou de constrangimentos vários? Um caso exemplar é o da jovem portuguesa que aos 16 anos conseguiu grande repercussão midiática para a sua luta contra o processo de adoção, decretado pela justiça, do filho de dois anos. Mãe e filho foram identificados no discurso noticioso pela divulgação dos seus nomes e imagem, incluindo no Público.

\section{A pobreza como estigma}

Jempson $(2005$, p. 1) considera que a estereotipização das crianças na mídia noticiosa é um fenômeno internacional no jornalismo. Isso seria um reflexo da percepção universal da infância como um tempo da inocência, o que provoca sentimentos de proteção, nostalgia e superioridade nos adultos. Por outro lado, quando as crianças transgridem esse papel (estabelecido para elas pelos adultos) despertam sentimentos de ansiedade e previsões negativas para o futuro. Ponte (2006, p. 3) chama 
atenção para a definição "do outro" - que representa um corpo estranho às considerações dominantes de identidade por parte de um determinado grupo - como estratégia de normalização, de exclusão e inclusão no discurso noticioso sobre o risco. É essa percepção do outro social (em oposição aos adultos, leitores de jornais, brancos de classe média) que vai influenciar a cobertura noticiosa sobre a violência envolvendo adolescentes a partir de enquadramentos que não promovem investimentos a longo prazo e encorajam campanhas punitivas contra grupos de jovens quase sempre pobres e marginalizados (HAMMARBERG, 1997, p. 248).

No Brasil, a Agência de Notícias dos Direitos da Infância (ANDI, 2005) e estudos acadêmicos (SERRA, 2002; 2004) denunciam a presença expressiva de discursos noticiosos que culpabilizam os adolescentes pela criminalidade, em notícias de destaque que privilegiam soluções simplistas como a redução da maioridade penal. Nestes, adolescentes em situação de exclusão aparecem frequentemente como os principais causadores da violência e são identificados a partir de termos pejorativos, que associam pobreza à criminalidade. Quando se trata de crianças e adolescentes de classes mais abastadas o tom da imprensa é de "perplexidade e revolta", enquanto o jovem pobre é visto como um bandido em potencial: "menor", "bandido", "trombadinha", "pivete" são termos utilizados exclusivamente para as classes excluídas (ANDI, 2005, p. 39).

Esta ideia de um "mundo dos outros" marcado por atributos como pobreza, violência, desvio e distância também marca o discurso noticioso dos jornais impressos em Portugal (PONTE, 2009, p. 2). Os atos delinquentes de jovens de estratos sociais mais elevados são caracterizados por atributos como leviandade, desvios de carácter, coisas da idade ou meras brincadeiras, enquanto a cor da pele e a origem social de outros jovens pode estimular a espetacularização exacerbada e apressada (CARVALHO; FERREIRA; SERRÃO, 2009). No mesmo sentido, Azeredo (2007, p. 205) afirma que o destaque dado à representação de "outros" jovens de cores que não a branca contribui para um ampliação da percepção do seu envolvimento no fenômeno da delinquência e consequente estigmatização. Por outro lado, Azeredo (2007, p. 205) aponta uma maior 
mediação entre os acontecimentos e o leitor no chamado jornalismo de referência do Público, que procura explicações, contextos políticos e legais da delinquência em cobertura mais aprofundada, por vezes temática, ancorada em estudos, acontecimentos de exceção ou datas comemorativas.

Se a princípio não são tão explícitos nos dois jornais discursos que promovam a estigmatização de crianças e adolescentes em situação de exclusão, uma análise mais apurada nos permite demarcar uma expressiva diferença de tratamento devotado às "nossas crianças" em contraposição às "crianças vistas como um outro social", especialmente em $O$ Globo. Num extremo está um jornalismo de proximidade (PONTE, 2005, p. 89) que privilegia um ponto de vista privado e individual sobre as crianças, a partir dos anseios e preocupações da "classe média" e de sugestões para melhor lidar com elas e educá-las. No outro, está a representação de crianças e especialmente adolescentes como um "outro social”, um corpo estranho, perigoso ou em vias de o ser, marcado pelo desvio, pobreza e distanciamento (PONTE, 2008).

Nos dois jornais, o termo "menor", por exemplo, adquire características estigmatizantes como aponta a nossa revisão de literatura (MULEIRO, 2006; ANDI, 2005), sendo utilizado quase que exclusivamente quando adolescentes representam uma ameaça ou crianças são vítimas de situações de exclusão social. Dois conjuntos de matérias publicadas por $O$ Globo são exemplares das diferenças significativas no enquadramento dos riscos sociais envolvendo adolescentes de meios socioeconômicos diferentes. De um lado, o combate à "desordem" e o restabelecimento da "autoridade" como solução possível em notícias sobre o problema de jovens dependentes de crack explorados sexualmente nas ruas do Rio de Janeiro. As informações sobre as histórias de vida destes se resumem a breves relatos sobre o envolvimento com as drogas e com a rede de exploração organizada por traficantes. De outro lado, a série "Jovens em risco" alinha com a geografia dos medos parentais que caracteriza a "classe média" (PONTE, 2006, p. 7) - em temas como acidentes no trânsito e segurança na Internet -, enfatizando o papel da família e dos próprios jovens na prevenção, recorrendo ao conselho de especialistas e à análise das políticas públicas para tratar dos problemas. Os 
contextos de vida dos jovens e as reflexões destes sobre os riscos em causa são relatados de forma detalhada.

\section{O direito à participação e a voz nas notícias}

Não são raros os estudos que apontam uma insuficiente visibilidade do ponto de vista das crianças nas notícias (FULLERTON, 2004; MCNAMARA, 2004; GOONASEKERA, 2001; VON FEILITZEN, 1998; FIJ, 2002; ANDI, 2005; PONTE, 2009). A sua voz estaria restrita a registos curiosos, simpáticos ou para colorir, em detrimento da sua análise sobre as questões que lhes dizem respeito (MULEIRO, 2006). Embora o direito à participação esteja consagrado na Convenção dos Direitos da Criança (Art. $12^{\circ}$ ), podemos falar de uma subrepresentação do papel das crianças como atores sociais participativos e consequentemente de uma escassez da voz destas, dos seus modos de pensar e de agir nas notícias (PONTE, 2008; ALTHEIDE, 2002; PONTE, 2006; CRITCHER, 2002; VON FELITZEN, 1998). Não há um ambiente profissional e social favorável para ouvir as crianças, apesar de repórteres e editores demonstrarem sensibilidade e interesse para fazê-lo (MARÔPO, 2011, p. 91).

Essas críticas se confirmam em parte no nosso corpus de análise. Do total de personagens representados, 127 no Público e 186 em $O$ Globo, identificamos no jornal português uma preponderância das crianças como vítimas (25 personagens ou 19,6\%) ou como alvo de cuidados e/ou atenção (19 personagens ou 14,9\%). A representação destas em papéis mais ativos, como o de estudante ( 5 casos ou 3,9\%) ou de ator social (4 exemplos ou 3,1\%) fica mais restrita a soft news especiais, com tempo maior de preparação e de convivência dos jornalistas com este grupo social

No geral, mesmo em peças que abordam questões ligadas ao comportamento e culturas juvenis, a voz dos adultos é acionada de forma prioritária em relação às das crianças no Público. Nesta perspectiva, encontramos apenas 19 personagens crianças ouvidas de forma ligeira para contar a sua experiência relativamente ao tema em 
questão (13,3\%), enquanto somente em um item sobre o dia escolar de 12 horas (P, 7/Fev) as crianças são ouvidas numa perspectiva de análise.

Os adolescentes são representados numa gama maior de papéis em relação às crianças no periódico português. Encontramos uma incidência aproximada de personagens como vítima (14 ou 11\%) ou como ameaça (10 ou 7,8\%) e uma representação bem mais significativa de personagens adolescentes como estudantes (25 ou 19,6\%) e como ator social (17 ou 13,3\%). Nesta perspectiva, a voz dos adolescentes está mais presente do que a das crianças: são 28 personagens ouvidos para contar a sua experiência relativamente ao tema em questão (22\%) e 24 numa perspectiva de análise do tema tratado $(18,8 \%)$. Em contrapartida, apenas quatro personagens adolescentes $(3,1 \%)$ estão na posição de alvo de cuidados e atenção.

Em $O$ Globo, à primeira vista pode causar surpresa a preponderância sobre as outras categorias da representação de personagens crianças (42 ou 22,5\%) e jovens (37 ou 19,8\%) como atores sociais, mas esses dados se devem principalmente, em ambos os casos, aos suplementos infanto-juvenis. No Globinho estão localizados 36 casos de crianças representadas como atores sociais, enquanto no Megazine estão 14 adolescentes nesta categoria. Nesse sentido, o periódico apresenta uma maior incidência do que o Público da voz de crianças e adolescentes numa perspectiva de análise do tema tratado: $34(18,2 \%)$ e $38(20,4 \%)$, respectivamente. Por outro lado, mesmo se excluirmos essas editorias da nossa análise encontramos uma incidência maior de personagens atores sociais no jornal brasileiro - 6 crianças e 23 jovens - do que no periódico português, com 4 e 17 respectivamente. Em $O$ Globo, encontramos ainda 12 personagens crianças $(6,4 \%)$ e 36 adolescentes $(19,3 \%)$ que contam as suas experiências sobre os temas em questão.

Motivado em parte por peças factuais que destacam a violência brasileira, encontramos em $O$ Globo também uma maior representação de crianças e jovens como vítimas, respectivamente $37(19,8 \%)$ e $25(13,4 \%)$ personagens. Assim como no jornal português, não há representação de crianças como ameaça no periódico brasileiro e, ao contrário do que aponta a revisão de literatura, encontramos apenas quatro personagens 
adolescentes identificados nesta categoria. Isso se deve principalmente por, em 2009, não ter sido noticiado nenhum caso de envolvimento de adolescentes com crimes violentos na primeira página em $O$ Globo. No entanto, os nossos estudos exploratórios sobre a publicação em anos anteriores e durante o ano de 2010 demonstram que, quando alguém com idade inferior a 18 anos é apontado como participante de atos violentos (especialmente homicídios), esse fato é insistentemente destacado em primeiras páginas o que leva a uma sobrerepresentação dos adolescentes como ameaça.

A dificuldade de OG de acompanhar aspectos relacionados com o quotidiano e os processos pedagógicos nas escolas de um país de dimensão continental como o Brasil pode ser apontada como uma das razões da baixa representação dos jovens como estudantes (11 ou 5,9\%) e mesmo da ausência da representação das crianças nesse papel. Além disso, o chamado jornalismo de proximidade é bem menos disseminado na publicação brasileira do que no periódico português: são apenas seis personagens crianças $(3,2 \%)$ e quatro adolescentes $(2,1 \%)$ representados como alvo de cuidados e atenção em $O$ Globo.

Por último, destacamos nos dois jornais o baixo índice de crianças ou adolescentes representados como alvo de políticas públicas, com quatro personagens no Público (3,1\%) e oito em $O$ Globo (4,3\%). A cobertura das ações e planos do governo, bastante frequente nos dois jornais, fica quase sempre restrita à voz das fontes oficiais e de especialistas sem o contraponto dos principais interessados.

\section{Conclusões}

Podemos afirmar que a relação entre os jornais de referência analisados e os direitos da criança representa um paradoxo. Por um lado, os dois periódicos contribuem para uma maior visibilidade pública de temáticas e problemas que afetam diretamente as crianças com chamadas em primeira página a cada 2,4 dias (OG) e 2,5 dias (P) mas, por 
outro lado, não são raras as situações em que estes desrespeitam os direitos infantis à privacidade, ao tratamento igualitário e à participação.

Nesse sentido, é fundamental que a legislação pertinente e os códigos de ética dos jornalistas sejam acionados (pela sociedade civil, pelos jornalistas como forma de auto-regulação e por instâncias do poder público) como instrumentos que garantam a crianças e adolescentes não serem identificados direta ou indiretamente em situações de risco, de conflito com a lei ou que possam causar prejuízos ao seu desenvolvimento saudável.

Além disso, o debate ético entre jornalistas e fontes de informação é essencial para evitar a "diabolização" de adolescentes envolvidos em atos violentos/delinquentes por meio da sobre-exposição, de enquadramentos promotores de "pânico moral" ou da divulgação massiva de soluções simplistas como o rebaixamento da maioridade penal em detrimento de outras perspectivas sobre o problema. É também importante para promover o respeito, cuidado e atenção especial às crianças de grupos minoritários (em situação de pobreza, imigrantes, minorias raciais, com necessidades especiais etc.) entre os jornalistas, incentivando para que divulguem histórias de sucesso sobre estas e para que evitem promover estereótipos.

Por último, ressaltamos a discrepância entre a imagem das crianças como atores sociais oferecida pela $\mathrm{CDC}$ e a representação dominante em $O$ Globo e no Público. Nos dois jornais predomina uma representação desse grupo social como recipiente das políticas governamentais, o que parece remeter para uma ideia de cidadania passiva, a partir de uma relação clientelar com o Estado. Atores sociais adultos de distintos campos têm o poder de sobrepor os seus pontos de vista, enquanto crianças e adolescentes, negligenciados como sujeitos de interesse político e social, são silenciados nas questões que lhes dizem diretamente respeito. Nesse sentido, chamamos atenção para a necessidade do jornalismo incluir com mais frequência a voz das crianças e para o papel central das fontes de informação institucionalizadas que precisam facilitar o acesso dos jornalistas às crianças e divulgar o ponto de vista delas nos seus relatórios e outros documentos. 
Em suma, a construção conjunta por jornalistas e atores sociais (incluindo crianças) de códigos de conduta nessa matéria e a divulgação eficiente dos já existentes seria uma contribuição fundamental para proteger e promover os direitos de crianças e adolescentes no discurso noticioso.

\section{Referências bibliográficas}

ALTHEIDE, David. Children and the discourse of fear. Symbolic Interaction, v. 25, n. 2, p. 229-250, 2000 .

AGÊNCIA DE NOTÍCIAS DOS DIREITOS DA INFÂNCIA. Infância na mídia: a criança e o adolescente no olhar da imprensa brasileira. Brasília: ANDI, 2005.

AZEREDO, Maria José Brites. A representação da delinquência juvenil nos media noticiosos: estudo de caso do Público e Correio da Manhã (1993-2003). Dissertação de mestrado em Ciências da Comunicação, Universidade Nova de Lisboa, Lisboa, 2007.

CANELA, Guilherme. Jornalismo, agendamento e a construção de uma esfera pública de discussões sobre a infância e adolescência: a experiência da agência de notícias dos direitos da infância. In: SAMPAiO, I.; CAVAlCANTE, A.; AlCÂNTARA, A. (Eds.) Mídia de chocolate. Rio de Janeiro: EPapers, 2006.

CARVALHO, M. J. L.; FERREIRA, L.; SERRÃO, J. Delinquência(s) e justiça: crianças e jovens em notícia. In PONTE, C. (ed.). Crianças e jovens em notícia. Lisboa: Livros Horizonte, 2009.

CRITCHER, C. Media, government and moral panic: the politics of paedophilia in Britain. Journalism Studies, v. 3, n. 4, p. 523-535, 2002.

FEDERAÇÃO INTERNACIONAL DOS JORNALISTAS. Information and child rights: the challenge of media engagement. Bruxelas: IFJ e Media Wise, 1997. Disponível em: $<$ http://www.mediawise.org.uk/display_page.php?id=127> Acesso em: 15. Jun. 2011.

FEDERAÇÃO INTERNACIONAL DOS JORNALISTAS. Child rights and the media - Putting children in the right. Guidelines for journalists and media professionals. Bruxelas: IFJ, 2002. Disponível em: $\quad<$ http://Www.unicef.org/magic/resources/childrights and media coverage.pdf $>$ Acesso em: 15. Jun. 2011.

FULLERTON, Romayne Smith. Covering kids: are journalists guilty of exploiting children? Journalism Studies, v. 5, n. 4, p. 511-524, 2004.

GOONASEKERA, Anura. Children in the news: an examination of the portrayal of children in television and newspapers in 13 Asian countries. Singapura: MCRAI Centre, 2001.

HAMMARBERG, Thomas. Children, the UN Convention and the media. The International Journal of Children's Rights, v. 5, p. 243-261, 1997.

JEMPSON, Michael. Slander, sentimentality or silence? What young people have to put up with from the media, 2005. Disponível em: <http://www.mediawise.org.uk/files/uploaded/Slander, \%20sentimentality\%20or\%20silence.pdf > Acesso em: 15. Jun. 2011. 
MARÔPO, Lidia. A mediação na construção de uma identidade de direitos da infância: representações jornalísticas de crianças e adolescentes em Portugal e no Brasil. Tese de doutoramento em Ciências da Comunicação, Universidade Nova de Lisboa, Lisboa, 2010.

MARÔPO, Lidia. Jornalistas e fontes de informação: constrangimentos e oportunidades para o agendamento dos direitos das crianças em Portugal e no Brasil. Estudos em Comunicação, n. 9, p. 81$102,2011$.

MARTINS, Paula. O mau trato infantil na comunicação social. Mealibra, Revista do Centro Cultural do Alto Minho, n. 8, série 3, 2001.

McNAMARA, Paul. Silent victims and pretty pops: the representation of young people in Irish national newspaper, 2004. Disponível em <http://www.nordicom.gu.se/cl/publ/electronic/PaulMcIreland1.pdf> Acesso em: 15. Jun. 2011.

MULEIRO, Hugo. Al margen de la agenda - Noticias, discriminación y exclusión. Buenos Aires: Fondo de Cultura Económica, 2006.

PONTE, Cristina. Crianças em notícia: a construção da infância pelo discurso jornalístico (1970-2000). Lisboa: ICS/Imprensa de Ciências Sociais, 2005.

Crianças em risco. O espaço latino-americano na imprensa portuguesa. Brasília: Actas do XXIX Intercom, 2006.

. Children in the News, Children and the news - notes from a Portuguese research. News on

Children, Youth and Media in the World, n. 1, 2008. Disponível em http://www.nordicom.gu.se/cl/publ/letter.php?id=97\#Children $\% 20<\mathrm{i}>\mathrm{in}</ \mathrm{i}>\% 20$ the $\% 20 \mathrm{News}$, $\% 20$ Children $\% 20<\mathrm{i}>$ and $</ \mathrm{i}>\% 20$ the $\% 20$ News $\% 20 \% 20$ Notes $\% 20$ from $\% 20 \mathrm{a} \% 20$ Portuguese $\% 20$ research $\% 20$ project (Acesso em 17 de junho de 2011).

Os nossos filhos e os filhos dos outros. Linguagens jornalísticas na imprensa. Braga: Actas do I Congresso sobre Intervenção com Crianças, Jovens e Família, 2009.

SERRA, Sónia. Comunicando a violência contra crianças brasileiras: dos protestos locais às denúncias em redes transnacionais. In PERUZZO, C.; COGO, D.; KAPLÚN, G. (eds.). Comunicação e movimentos populares: quais redes? São Leopoldo: Ed. Unisinos, 2002.

O papel político do jornalismo e as representações de "menores" vítimas da violência. Salvador: Actas do $2^{\circ}$ Encontro Nacional de Pesquisadores em Jornalismo, 2004.

VON FEILITZEN, Cecilia. Introduction. VON FELITZEN, C.; CARLSSON, Ulla (Eds.) Children and media violence. Goteborg: Nordicom, 1998.

Este artigo e todo o conteúdo da Estudos em Jornalismo e Mídia estão disponíveis em http://www.periodicos.ufsc.br/index.php/jornalismo/index

Estudos em Jornalismo e Mídia está sob a Licença Creative Commons 
${ }^{\text {i }}$ Quando são foco central de notícias sobre os seus modos de viver e de pensar acerca de temas gerais e de questões que lhes dizem diretamente respeito. 